\title{
COMPOSIÇÃO EM ÁCIDOS GRAXOS DE ŌLEOS VEGETAIS E GORDURAS ANIMAIS *
}

\author{
H. Fonseca \\ L. E. GutierReZ
}

\begin{abstract}
RESUMO
Seis tipos de bleos comestiveis (de milho, de sofa, de oliva, de algodão, de amendoim e de girassol) e duas gorduras de origem animal (manteiga e banha) foram analisados quanto aos seus teores em ácidos graxos, por meio da cromatografia em fase gasosa.

O bleo de girassol apresentou o maior teor de ácidos graxos insaturados $(86,10 \%)$ seguido pelo óleo de soja $84,15 \%$ e sendo o 6leo mais saturado, o de algodão (24,23\%). A manteiga apresentou grande número de ácidos graxos, desde 4 até 22 átomos de carbono, apresentando $58,00 \%$ de saturados. A banha de porco apresentou $39,82 \%$ de ácidos graxos saturados. Os ácidos graxos mais abundantes foram o olêico e linolêico, entre os insaturados e palmítico, entre os saturados.
\end{abstract}

\section{INTRODUÇAOO}

A análise de ácidos graxos por cromatografia em fase gasosa permite identificar, com bastante segurança, ácidos graxos saturados e insaturados, de cadeia curta e longa, presentes em óleos e gorduras. Vários métodos, usados anteriormente, como destilação e cristalização fracionadas e cromatografia em papel de filtro não eram tão eficientes e rápidos como o da cromatografia em fase gasosa.

Pesquisas têm demonstrado haver uma relação entre a composição em ácidos graxos dos óleos e gorduras e o nível de colesterol do sangue. MC OSKER ef al. (1962) relataram que dietas contendo $25 \%$ ou menos de ácidos graxos saturados causaram uma redução significativa no nível de colesterol do sangue.

- Entregue para publicação em 27/12/1974.

* Departamento de Tecnologia Rural da HSAIQ.

*** Bolsista de Aperfeiçoamento da Fundação de Amparo a Pesquisa do Estado de Săo Paulo, junto ao Departamento de Tecnologia Rural da ESALQ. 
NEWLANDER \& ATHERTON (1964) destacaram a presença de 40 diferentes ácidos graxos na gordura do leite de vacas, sendo 18 saturados e 22 insaturados. A dieta das vacas pode afetar a proporção dos ácidos graxos da gordura do leite. Confirmando este fato, NOBLE et al. (1969) constataram que a adição de ácido palmítico na ração provocou uma redução significativa nos ácidos graxos de cadeia menor do que 16 átomos de carbono e também dos ácidos esteárico e linolêico, e um aumento nos teores de ácidos palmítico e palmitolêico.

QURESHI ef al. (1971) relataram que o teor de ácido linolêico foi significativamente reduzido na gordura do leite de vacas alimentadas com feno.

A gordura dos suinos é afetada pelo sexo e dieta (KOCH et al., 1968), sendo que os ácidos graxos insaturados são preferentemente depositados nos tecidos de suinos (DAHL et al. 1965).

No presente trabalho procuramos identificar e quantificar ácidos graxos de alguns óleos vegetais e gorduras animais existentes no comércio, para verificar-se condições várias como, clima, solo, alimentação e outros fatores poderiam modificar a composição dos referidos óleos e gorduras, cujas composições médias são citadas em SWERN (1964) e FLORKIN \& STOTZ (1965).

\section{MATERIAL E MÉTODOS}

Foram analisadas 6 amostras de óleos de oliva, algodão, soja, girassol, amendoim e milho e duas amostras de gorduras animais (manteiga e banha de porco) todos obtidos no comércio.

Para a cromatografia em fase gasosa, as amostras foram esterificadas pelo método de LUDDY et al. (1960) a fim de se obter os ésteres metílicos dos ácidos graxos. Os ácidos graxos foram identificados por comparação com ésteres metílicos de ácidos graxos puros e pela distância de retenção segundo método de HAKEN (1966).

Todas as amostras foram analisadas em triplicata, e as áreas dos picos foram calculadas por triangulação.

As condições da análise cromatográfica foram as seguintes:

- cromatógrafo de gás CG-15, com detetor de ionização de chama.

- gás de arraste, nitrogênio a $40 \mathrm{ml} / \mathrm{min}$.

- colunas gêmeas de 2 metros de comprimento e 3/16" de diâmetro interno, com dietileno glicol succinato a $18 \%$ sobre Gas Chron P A/W DMCS como suporte.

- temperatura da coluna: $180^{\circ} \mathrm{C}$ para óleos vegetais e banha, e variando de $60^{\circ}$ a $180^{\circ} \mathrm{C}$ para manteigas. 
- temperatura do detetor: $240^{\circ} \mathrm{C}$.

- temperatura do vaporizador: $220^{\circ} \mathrm{C}$.

\section{RESULTADOS E DISCUSSÁO}

Os resultados das análises são os dos QUADROS 1 e 2 .

QUADRO 1: Composição em ácidos graxos dos óleos vegetais (\% em peso, do total de ácidos graxos)

\begin{tabular}{|c|c|c|c|c|c|c|}
\hline \multirow{2}{*}{$\begin{array}{l}\text { Acido } \\
\text { Graxo (1) }\end{array}$} & \multicolumn{6}{|c|}{ OLEOS VEGETAIS } \\
\hline & Oliva & Milho & Girassol & Soja & Algodão & Amendoim \\
\hline $14: 0$ & - & - & 0,08 & 0,20 & 0,80 & 一 \\
\hline $16: 0$ & 14,23 & 14,03 & 8,36 & 11,35 & 20,13 & 11,42 \\
\hline 18:0 & 3,41 & 3,33 & 5,03 & 4,15 & 3,10 & 2,82 \\
\hline $20: 0$ & 0,58 & 1,00 & 0,43 & 0,15 & 0,20 & 2,33 \\
\hline 22:0 & - & - & - & - & - & 2,08 \\
\hline $\begin{array}{l}\text { Total } \\
\text { Saturados }\end{array}$ & 18,26 & 18,36 & 13,90 & 15,85 & 24,23 & 18,65 \\
\hline $14: 1$ & - & - & 0,04 & - & - & - \\
\hline $16: 1$ & 2,52 & 0,20 & 0,05 & 0,05 & 1,43 & - \\
\hline $18: 1$ & 71,10 & 35,08 & 27,65 & 25,30 & 22,86 & 41,69 \\
\hline 18:2 & 6,76 & 44,40 & 56,30 & 50,60 & 50,16 & 38,46 \\
\hline $18: 3$ & 1,36 & 1,96 & 2,06 & 8,20 & 1,32 & 1,17 \\
\hline Total & & & & & & \\
\hline Insaturados & 81,74 & 81,64 & 86,10 & 84,15 & 75,77 & 81,32 \\
\hline
\end{tabular}

(1) número de átomos de carbono: número de duplas ligaçães 
QUADRO 2: Acidos graxos das manteigas e banhas

(\% em peso, do total de ácidos graxos)

\begin{tabular}{|c|c|c|}
\hline \multirow[b]{2}{*}{ Acido graxo (1) } & \multicolumn{2}{|c|}{ GORDURAS ANIMAIS } \\
\hline & Manteiga & Banha \\
\hline 4:0 & 2,00 & - \\
\hline $6: 0$ & 1,00 & - \\
\hline $8: 0$ & 1,00 & - \\
\hline $10: 0$ & 1,50 & 0,16 \\
\hline $12: 0$ & 1,50 & 0,19 \\
\hline $13: 0$ & 0,20 & - \\
\hline $14: 0$ & 9,00 & 1,59 \\
\hline $15: 0$ & 1,90 & - \\
\hline $16: 0$ & 24,00 & 22,40 \\
\hline $17: 0$ & 1,00 & - \\
\hline $18: 0$ & 13,00 & 15,27 \\
\hline $19: 0$ & 0,40 & - \\
\hline $20: 0$ & 0,50 & 0,20 \\
\hline 22:0 & traços & traços \\
\hline Total saturados & 58,00 & 39,82 \\
\hline $6: 1$ & 0,01 & - \\
\hline $8: 1$ & 0,02 & - \\
\hline $10: 1$ & 0,20 & - \\
\hline $10: 2$ & traços & - \\
\hline $10: 3$ & 0,09 & - \\
\hline $12: 1$ & 0,20 & - \\
\hline $12: 2$ & 0,20 & - \\
\hline $12: 3$ & 0,40 & - \\
\hline $14: 1$ & 0,80 & 0,15 \\
\hline $14: 2$ & 0,45 & - \\
\hline $14: 3$ & 0,50 & - \\
\hline $16: 1$ & 2,50 & 4,20 \\
\hline $16: 2$ & 0,50 & 0,33 \\
\hline $16: 3$ & traços & 0,43 \\
\hline $18: 1$ & 32,00 & 40,40 \\
\hline $18: 2$ & 3,00 & 12,43 \\
\hline $18: 3$ & 1,00 & 2,23 \\
\hline $20: 1$ & traços & 0,01 \\
\hline Total insaiturados & 41,75 & 60,18 \\
\hline
\end{tabular}

(1) número de átomos de carbono : número de duplas ligações 
Os resultados contidos no QUADRO 1, indicam que, dentre os analisados, o óleo de girassol seria, segundo McOSKER et al. (1962) o mais recomendável para alimentação pois é o que apresenta o maior teor de ácidos graxos insaturados $(86,10 \%)$. Os óleos de oliva e milho apresentaram teores de insaturados muito próximos ( $81,74 \%$ e $81,64 \%$, respectivamente), entretanto o óleo de milho apresenta maior teor de ácido linolêico. 0 óleo de algodão apresentou o maior teor de saturados dos óleos estudados $(24,23 \%)$ seguido pelo óleo de amendoim com 18,65\%.

Os resultados obtidos, quando comparados com a literatura consultada aproximam-se dos obtidos por outros autores, como SWERN (1964) e FLORKIN \& STOTZ (1965), com exceção dos resultados para óleo de amendoim que apresenta um nível maior de ácido linolêico do que o apresentado por esses autores.

Observando-se o QUADRO 2, notamos o grande número de ácidos graxos na manteiga (32 no total), embora NEWLANDER \& ATHERTON (1964) destaquem a presença de 40 ácidos graxos na manteiga. As nossas condições de trabalho não permitiram detectar os restantes.

A manteiga apresentou ácidos graxos saturados em maior teor do que insaturados, fato também observado por NOBLE et al. (1969) e QURESHI ef al. (1971).

A banha apresentou teor de ácidos graxos insaturados maior que o de saturados, tendo sido detectados os seguintes ácidos graxos em maior proporção: palmítico, esteárico, palmitolêico, olêico e linolêico.

\section{CONCLUSÓES}

Dos resultados obtidos, pôde-se extrair as seguintes conclusões:

1. O óleo de girassol apresentou o maior teor em ácidos graxos insaturados $(86,10 \%)$ seguido pelo óleo de soja $(84,15 \%)$.

2. Dos óleos vegetais, o de algodão apresentou o maior teor de ácidos graxos saturados $(24,23 \%)$.

3. Dos 32 ácidos graxos da manteiga, 14 são saturados e 18 são insaturados, com um total de $58,00 \%$ de saturados.

4. A banha apresentou $39,82 \%$ de ácidos graxos saturados.

5. O ácido olêico predominou em quase todas as amostras analisadas.

\section{SUMMARY}

\section{"FATTY ACID COMPOSITION OF VEGETABLE OILS AND ANIMAL FATS"}

The fatty acid composition of different kinds of edible vegetable oils 
(corn, soybean, olive, cottonseed, peanut and sunflower seed) and animal fats (butter and lard) was determined by gas liquid chromatography.

The sunflower seed oil presented the highest yield of unsaturated acids (86.10\%) followed by the soybean oil (84.15\%), while Cottonseed oil showed the highest saturation (24.23\%). Butterfat revealed great number of fatty acids (32) from 4 to 22 including several fatty acids with odd number of carbon atoms.

Butterfat showed $58.00 \%$ of saturation while lard, $39.82 \%$.

\section{LITERATURA CITADA}

DAFL, O. \& PEARSON, 1965 - Properties of animal depot fat in relation to dietary fat. J. Sci. Food Agric., $16: 452-457$.

FLORIKIN, M. \& E. H. STOTZ, 1965 - «Comprehensive Biochemistry». Vol. 6. Elsevier Publishing. New York.

HAKEN, J. K., 1966 - Retention time relationship in the gas chromatography of the methyl esters of fatty acids. J. Chromatog., $23: 375-381$.

KOCH, E. E., A. F. PARR \& R. A. MERKEL, 1968 - Fatty acid composition of the inner and outer layers of porcine backfats as affected by energy level, sex and sire. J. Food Sci., $33: 176-179$.

LUDDY, F. E., R. A. BARFORD \& R. W. RIEMENSCHNEIDER, 1960 - Direct conversion of lipid components to their methyl esters. J. Am. Oil Chem. Soc., 137 : 447-451.

MCOSKER, D. E., F. H. MATTRON, H. B. SWERINGEN \& A. M. KLIGMAN, 1962 - The influence of partially hydrogenated dietary fats on serum cholesterol levels. J. Am. Med. Assoc., 180 : 380-385.

NEWLANDER, J. A. \& H. V. ATHERTON, 1964 - «The Chemistry and Testing of Dairy Products». Olsen Publishing. Wisconsin, E. U. A.

NOBLE, R. C., W. STEELE \& H. J. MOORE, 1969. The effects of dietary palmitic and stearic acids on milk fat composition in the cow. J. Dairy Res., $36: 375-381$.

QURESHI, S. R., D. E. WALDERN, T. HBLOSSER \& R. W. WALLENIUS, 1971 Effects of diet on proportion of blood plasma lipids and milk lipids of the lactating cow and their long-chain fatty ocids composition. J. Dairy Sci., 55 : 93-101.

SWERN, D. (ed.), 1964 - «Bailey's Industrial Oil and Fat Products». Interscience Publishing, New York. $3^{\text {rd }}$ Edition. 